\title{
Region EKC for Air Pollution: Evidence from China
}

\author{
Wenzhong Wang ${ }^{1}$ \\ ${ }^{1}$ College of Economics and Management, Nanjing University of Aeronautics and Astronautics, Nanjing, China \\ Correspondence: Wenzhong Wang, College of Economics and Management, Nanjing University of Aeronautics \\ and Astronautics, Nanjing 210016, China. E-mail: w_wenzhong@163.com
}

$\begin{array}{lc}\text { Received: February 28, } 2018 \quad \text { Accepted: March 9, } 2018 \quad \text { Online Published: March 30, } 2018 \\ \text { doi:10.5539/ep.v7n1p46 } & \text { URL: https://doi.org/10.5539/ep.v7n1p46 }\end{array}$

\begin{abstract}
In recent years, with the increasing care of environmental issues, the relationship between air quality and the level of economic development has been widely studied. In the present paper, a traditional EKC model and two improved model are built to analyze the relationship between the air quality index and the per capita GDP with the panel data of 41 major cities during 2000 and 2015 of China. By the co-integration analysis, the results show that under the three-square EKC model, the relationship between the AQI and GDP per capita satisfies the $\mathrm{N}$-shaped environment Kuznets curve and there exist two turning points. In the form of the traditional two-square EKC model, the two variables are satisfied with the U-shaped relationship. The results of the growth rate model also show that the two variables are satisfied with the U-shaped relationship, but there are differences among the turning points.
\end{abstract}

Keywords: AQI, GDP per capita, EKC, economic growth, regression analysis

\section{Introduction}

In recent years, the environmental problems in China, mainly due to the economic development, become more and more serious, especially for the air quality issues. For example, thicker haze and frog seriously affect the life of the public health, which was received an increasing attention both by the government and residents.

China has maintained a high speed of economics growth, and the contribution rate to the world economy continues to increase, while its quality of life and happiness index didn't significantly increase. Therefore, it's necessary to detect the relationship between environmental quality and economic growth in China and the turning point of EKC are getting more and more. Environment Kuznets Curve (EKC) is developed on the basis of the Kuznets curve, which is first proposed by the famous American economist Kuznets to reflect the relationship between economic growth and income distribution. The Environment Kuznets Curve describes the inverted U relationship between environmental index and per capita income (Grossman G M; Krueger A B, 1991). That is to say, in a certain period of time the environmental quality continues to deteriorate with the economic development, and when the economy develops to a certain extent, the Kuznets curve will reach an turning point, which is the highest point of the inverted $U$ curve. But after this, the quality of the environment will be improved with economic development. At present, questions like what's the relation between the environment quality and the economic development in China, and how to adjust the strategy of economic development and protect environment are urgent to be ansered.

Until now the empirical research about environment and economic development in China mainly focus on energy consumption and economic growth as well as research on the single air pollution index toward economic development such as carbon emission. To our understanding, till now there is no research covering multiple environmental pollution elements. In this paper, the Air Quality Index (AQI) is used as a measure of the degree of air pollution to study Interaction between air pollution and economic development. The air quality index is a dimensionless index to quantitatively describe the status of air quality, and the main pollutants in air quality assessment are fine particulate matter, respirable particulate matter, sulfur dioxide, nitrogen dioxide, ozone, carbon monoxide and other six and so on. In the first half of 2012, the Chinese government introduced the indicator of air quality index (AQI) to replace the original air pollution index (API).

\section{Literature Review}

The Environmental Kuznets Curve (EKC) was first proposed by Grossman and Krueger according to the Kuznets Curve (KC) in economics, and was used to study the environmental impact of the North American Free 
Trade Agreement. And after that, many empirical studies have shown that the relationship between the majority of environmental quality indicators and per capita income is inverted " $U$ " type. The research about EKC in the world can be divided into the static model and the dynamic model. The representatives of the static regression model are Lopez (1994) and McConnel (1997). Lopez discussed the problem of the maximization of social welfare through the study of the relationship between social welfare and income, pollution and price, and found that if the social welfare satisfies the non-homogeneity assumption, we can get the "U" type of Kuznets curve. McConnel(1997) studied on the relationship between pollution and income from the perspective of individual and found that when the mixed partial derivative of the utility function toward pollution consumption has a process from a positive one to a negative, the relationship between pollution and income is inverted U-shaped type. Andreoni and Levinson (2001) simplified McConndl's research and assumed that utility functions and pollution functions are simple linear functions, and they concluded that if environmental governance meets the conditions of increasing scale, then EKC curves can be launched without consideration of cost function.

The relationship between environmental quality and economic growth is not always $U$ or inverted U-shaped type, but also in other shapes. Magnani (2001) analyzed the basic elements of reducing environmental pollution on the basis of the EKC, and found that the income distribution function is the decisive factor of the relationship between economic growth and environmental quality, but the economic growth and environmental quality are not always satisfied with the EKC curve. Hannes Egli (2001) found that the EKC curve does not exist by studying the data of environmental pollution and economic development in Germany. Zhao and Chen (2015) analyzed the amount of industrial pollution emissions in the time series from 2002 to 2013year based on nonlinear science basic principle and research hypotheses. They estimated the EKC curve of industrial pollution emissions combined with the regional economic development, and concluded that the relationship between regional economic growth, export trade and industrial pollution emissions has nonlinear, dynamic and complex characteristics. The relationship between the economic development and the environment does not always appear in the inverted U type. Most pollutants do not exhibit typical environmental Kuznets curve characteristics, but most pollutants increase with the development of economy. In the long run, the transformation characteristics of EKC curve may appear. The relationship between economic development and environment may have a traditional inverted-U relationship, but there may also be other forms, such as the trend of " $\sim$ " or monotonous increasing trend (Zhao, Li, \& Wang, 2005).

The latest research like Danish et al. (2017), they analyzed the relationship between renewable energy and non-renewable energy consumption in Pakistan and found that renewable energy plays a dominant role in reducing carbon dioxide emission and non-renewable energy consumption indeed the main culprit for promoting carbon dioxide emission. As the development of EKC curve, it also got some critical views. Zhong and Zhang (2010) summarized three defects based on the related literatures on the environmental Kuznets curve: first, the one-way characteristic and the assumption that homogeneity in different countries are not realistic, which imply the vulnerability of the EKC relationship between the environment and the income or economic development level; second, the general method of economic development and the environment is a "black box" method, can not reveal the internal mechanism; third, the shape of the EKC curve and turning point are centered, which may overlook its mechanism.

\section{Data and Model}

\subsection{Data}

This paper mainly adopts two kinds of index data, one kind of data is used to reflect the level of economic development which is represented by GDP per capita, and the other one is used to reflect the air quality which is represented by air quality index (AQI). The data of GDP per capita are collected from the statistics of the main cities in China's urban statistical yearbook, and the data of AQI are derived from the Ministry of Environmental Protection. In order to eliminate price factors in this study, the data of GDP were converted into real GDP as the base year of 2000. In order to ensure the integrity and availability of data, 41 main cities are selected as objects in this paper to analyze the balance panel data. The selected cities are Beijing, Chengdu, Dalian, Fuzhou, Guangzhou, Guiyang, Harbin, Haikou, Hangzhou, Hefei, Hohhot, Jinan, Kunming, Lhasa, Lanzhou, Nanchang, Nanjing, Nanning, Nantong, Qingdao, Xiamen, Shantou, Shanghai, Shenzhen, Shenyang, Shijiazhuang, Suzhou, Tianjin, Wenzhou, Urumqi, Wuhan, Xi'an, Xining, Yantai, Yinchuan, Zhanjiang, Changchun, Changsha, Zhengzhou, Chongqing and Zhuhai.

The two index data are taken from the data of a time series from year of 2000 to 2015 . There are a few missing values in the data, we complete the missing value according to the growth rate over the years. Among them, there is a big difference between AQI and the original air pollution index (API). The reference standard of AQI 
grading calculation is the new ambient air quality standard (GB3095-2012). The pollutants participating in the evaluation are six items, which are SO2, NO2, PM10, PM2.5, O3 and CO. The comprehensive value of these six items can be more representative as the evaluation index of air quality.

\subsection{Models}

At this stage, the study of EKC curve is mostly using the logarithmic linear model of its square, and a few scholars consider adding three squares to analyze it. In general, the more the number of squares is considered, the more dimensions it can reflect. If we only consider the change of GDP per capita, we can get the constant value of AQI elasticity coefficient, if we add the square term, we can get the change of elasticity value, and if we add cubic item, we can know the intensity of elastic change. In this paper, firstly we used the logarithmic linear model of Shafik and Bandyopadhyay's (1992), and then we established the traditional two-square EKC model to make a comparison, which are as follow:

$$
\ln A Q I_{i t}=\alpha_{0}+\alpha_{1} \ln p g d p_{i t}+\alpha_{2}\left(\ln p g d p_{i t}\right)^{2}+\alpha_{3}\left(\ln p g d p_{i t}\right)^{3}+\varepsilon_{i t}
$$

Where $A Q I_{i t}$ is air quality index; $p g d p_{i t}$ is GDP per capita; $\varepsilon_{i t}$ is random error term, $\alpha_{0}$ is intercept; $\alpha_{1}, \alpha_{2}$ and $\alpha_{3}$ are parameters to be estimated; the subscript $\mathrm{i}=1,2, \ldots \mathrm{N}$ represent regions; $\mathrm{t}=1,2, \ldots \mathrm{T}$ represent years. In this paper, firstly we estimated for the three-square term, if it is not significant, then the three-square term is eliminated and the two-square term is re-estimated. If it is not significant, then we estimated the linear term, if it is still not significant, all of them are eliminated. It shows that there are other factors that are not significant, and the model should be estimated again. If the shape of the curve is closely related to the value of the three parameters to be estimated, it can be divided into the following cases:

1) $\beta_{1}=\beta_{2}=\beta_{3}=0$, there is no relation between AQI and pgdp.

2) $\beta_{1}<0, \beta_{2}=\beta_{3}=0$, AQI decrease with the increase of pgdp.

3) $\beta_{1}>0, \beta_{2}=\beta_{3}=0$, AQI increase with the increase of pgdp.

4) $\beta_{1}<0, \beta_{2}>0, \beta_{3}=0$, there is a "U" shaped relationship between AQI and pgdp.

5) $\beta_{1}>0, \beta_{2}<0, \beta_{3}=0$, there is an inverted "U" shaped relationship between AQI and pgdp.

6) $\beta_{1}<0, \beta_{2}>0, \beta_{3}<0$, there is an inverted " $N$ " shaped relationship between AQI and pgdp.

$\beta_{1}>0, \beta_{2}<0, \beta_{3}>0$, there is an "N" shaped relationship between AQI and pgdp.

To make a comparison, this paper also estimated a traditional two-square EKC model, see formula (2):

$$
\ln A Q I_{i t}=\alpha_{0}+\alpha_{1} \ln p g d p_{i t}+\alpha_{2}\left(\ln p g d p_{i t}\right)^{2}+\varepsilon_{i t}
$$

In order to test the relation of growth rates between the air pollution and income per capita, we set a growth rates model based on Anjume et al. (2014) which given as follow:

$$
\hat{A}_{i}=\beta_{0}+\beta_{1} \widehat{G}_{i}+\beta_{2} \widehat{G}_{i} G_{i, 0}+\beta_{3} G_{i, 0}+\beta_{4} A_{i, 0}+\varepsilon_{i}
$$

Where $\hat{A}_{i}$ represents the growth rate of AQI, and $\hat{A}_{i}=\left(A_{i, t}-A_{i, 0}\right) / T ; \hat{G}_{i}$ represents the growth rate of GDP per capita, and $\widehat{G}_{i}=\left(G_{i, t}-G_{i, 0}\right) / T$; here $A$ and $G$ are the logarithmic forms of AQI and GDP per capita respectively. We set 2000 as an initial year, and T represents the last year, $i=1,2, \ldots \ldots N(N=41)$ represent the cities. In equation(3), parameter $\beta_{0}$ is the endogenous growth of air quality index, it is a part that cannot be affected by economic growth, that is, the growth rate of air quality index when economic growth is $0 ; \beta_{1}$ is an elastic to be estimated between the two growth rate variables; $\beta_{2}$ is an estimate of the interaction between two growth rate variables; $\beta_{3}$ and $\beta_{4}$ are the estimates of the relationship between the AQI growth rate and the initial variables of AQI and GDP per capita. In order to make a comparison, this paper also estimates the growth model with only two variables, which is given as follow:

$$
\hat{A}_{i}=\beta_{0}+\beta_{1} \widehat{G}_{i}+\beta_{2} \widehat{G}_{i} G_{i, 0}+\varepsilon_{i}
$$

\section{Empirical Analysis}

\subsection{Unit Root Test}

The panel data from the year of 2000 to 2015 is applied, some non-stationary economic time series show a common tendency which are not directly related, though there is a high $\mathrm{R}$ square in the regression model with no 
practical significance. In order to prevent the phenomenon of false regression, it is necessary to do the unit root test before the analysis. And after verifying the condition of stability of the observation data, the measurement can be carried out. Generally, the raw data is easier to meet some measurement requirements with the logarithmic treatment without changing the co-integration relationship. Since the premise of the research of co-integration relation between variables is uniformity integrated, in this paper, the unit root test of $\ln \mathrm{AQI}$, $\ln$ gdp, $(\ln p g d p)^{2}$ and $(\operatorname{lnpgdp})^{3}$ was carried out by Eviews8.0, and the results are as follows:

Table 1. Results of unit root test of the original sequence

\begin{tabular}{cccccccccc}
\hline & \multicolumn{2}{c}{$\ln$ lnqi } & \multicolumn{2}{c}{$\ln p g d p$} & \multicolumn{2}{c}{$(\ln p g d p)^{2}$} & \multicolumn{3}{c}{$(\ln p g d p)^{2}$} \\
Methods & $\mathrm{t}$ & $\mathrm{P}$ & $\mathrm{t}$ & $\mathrm{P}$ & $\mathrm{t}$ & $\mathrm{P}$ & $\mathrm{t}$ & $\mathrm{P}$ \\
\hline Levin,Lin \& Chu & -0.7366 & 0.2307 & -11.3723 & 0.0000 & -8.1753 & 0.0000 & -4.2910 & 0.0000 \\
Im, Pesaran and Shin W-stat & -2.3009 & 0.0107 & -2.2059 & 0.0137 & 1.3437 & 0.9105 & 5.0607 & 1.0000 \\
ADF-Fisher Chi-square & 109.193 & 0.0240 & 157.765 & 0.0000 & 122.5650 & 0.0025 & 90.7058 & 0.2392 \\
PP-Fisher Chi-square & 92.9797 & 0.1912 & 131.471 & 0.0004 & 75.7246 & 0.6739 & 46.3843 & 0.9995 \\
\hline
\end{tabular}

From table1 we can see, though the sequence data of lngdp under the four test forms are stable, the sequence data of lnaqi, $(\ln p g d p)^{2}$ and $(\ln p g d p)^{3}$ are non-stationary. As co-integration analysis does not meet the conditions, the unit root test of the three sequences of first order difference need to be done. The results are as the table 2:

Table 2. Results of unit root test of the first order difference

\begin{tabular}{ccccccc}
\hline & \multicolumn{2}{c}{$\Delta \ln a q i$} & \multicolumn{2}{c}{$\Delta(\ln p g d p)^{2}$} & \multicolumn{2}{c}{$\Delta(\ln p g d p)^{3}$} \\
Methods & $\mathrm{t}$ & $\mathrm{P}$ & $\mathrm{t}$ & $\mathrm{P}$ & $\mathrm{t}$ & $\mathrm{P}$ \\
\hline Levin,Lin \& Chu & -14.6743 & 0.0000 & -5.6563 & 0.0000 & -7.8092 & 0.0000 \\
Im,Pesaran and Shin W-stat & -11.5832 & 0.0000 & -2.4131 & 0.0079 & -4.1530 & 0.0000 \\
ADF-Fisher Chi-square & 289.2860 & 0.0000 & 121.579 & 0.0030 & 144.787 & 0.0000 \\
PP-Fisher Chi-square & 317.3790 & 0.0000 & 166.662 & 0.0000 & 181.566 & 0.0000 \\
\hline
\end{tabular}

From the table 2 we can see the lnaqi sequence of first order difference are stable, and the first order difference sequence of $\operatorname{lngdp},(\operatorname{lnpgdp})^{2}$ and $(\operatorname{lnpgdp})^{3}$ are also stable. Thus the sampling meets the co-integration conditions and the co-integration regression analysis is suitable.

\subsection{Co-integration Test}

In this paper, the Pedroni test method is used to carry out co-integration test between variables, Pedroni test method can be used to test the data of heterogeneous panel, which is widely used in the field of statistics. Its original assumption is that if the test value is less than the critical value, there is no co-integration relationship at a given significance level. The result of the co-integration regression analysis is showed in table 3 .

Table 3. Results of Pedroni test

\begin{tabular}{lcccc}
\hline & Statistic & Prob. & Weighted Statistic & Prob. \\
\hline Panel v-Statistic & 2.2686 & 0.0116 & 0.8251 & 0.2047 \\
Panel rho-Statistic & -4.1023 & 0.0000 & -4.7606 & 0.0000 \\
Panel PP-Statistic & -4.2410 & 0.0000 & -5.3440 & 0.0000 \\
Panel ADF-Statistic & -2.6270 & 0.0043 & -3.7639 & 0.0001 \\
Group rho-Statistic & 0.1007 & 0.5401 & & \\
Group PP-Statistic & -0.8522 & 0.1971 & & \\
Group ADF-Statistic & -2.2374 & 0.0126 & & \\
\hline
\end{tabular}


There are seven cointegration test statistics in Pedroni test method, generally speaking, the model can be considered to be reasonable when the majority of the test statistics are significant. Therefore, the cointegration conditions are satisfied between the variables in this paper, and the regression analysis can be carried out.

\subsection{Regression}

Considering whether the regression model is a form of fixed or random effects, the Hausman test of the variable is carried out in this paper. And the result shows that $\mathrm{t}=9.0299(\mathrm{P}=0.0289)$, so the null hypothesis can be rejected, and we adopt the fixed effect model (FE) here. The final regression results are shown in Table 4.

Table 4. Results of regression

\begin{tabular}{lcc}
\hline & Equation $(2)$ & Equation $(1)$ \\
\hline$(\ln p g d p)^{3}$ & & $-0.0250^{* *}(-2.3250)$ \\
$(\ln p g d p)^{2}$ & $0.0309^{* * *(2.6445)}$ & $0.7947^{* *}(2.4175)$ \\
$\ln p g d p$ & $-0.6771^{* * *(-2.9390)}$ & $-8.4678^{* *}(-2.5212)$ \\
$\mathrm{c}$ & $7.9906^{* * *(6.5730)}$ & $34.4732^{* * *}(3.0096)$ \\
$\mathrm{R}^{2}$ & 0.8494 & 0.8509 \\
F-statistic & 56.2187 & 55.7634 \\
D-W & 1.3864 & 1.4004 \\
Shape of EKC curve & $\mathrm{U}$ & $\mathrm{N}$ \\
Turning points (RMB) & 57593.57 & $21178.40 \& 78339.99$ \\
\hline
\end{tabular}

Note. The data in the parentheses behind the estimated values are $\mathrm{t}$ statistics, significance levels of regression coefficients: $* 10 \%, * * 5 \%, * * * 1 \%$. The final estimated value data retained four bits after the decimal point, and the $\mathrm{T}$ value retained the bits after the decimal point.

The estimated results in table 4 show that the estimated values of each parameter have reached a more significant level. The difference is that the shape of the EKC curve obtained by the equation (2) is U-shaped, and the result of the equation (1) is the N-shaped type. Although the form of expression is different, the two shapes can explain the same effect. The results of equation (2) show that the relationship between air quality index and economic development is a U-shaped type, that is to say, in the early stage of economic development, the air quality will continue to improve with the development of economy, AQI continued to decline, but when the economy develops to a certain extent will reach a critical, and after this point, the air quality will get worse with the development of economy. Equation (2) shows that the turning point is the point that GDP per capita reaches 57593.57 yuan, that is to say, the air quality in cities of China improved with the economic development, but when the GDP per capita comes up to 57593.57 yuan, the air quality will continue to deteriorate because of the negative external effects of economic development. Equation (1) shows that the relationship between air quality index and economic development is an N-shaped type, that is to say, in the early stage of economic development, the air quality will continue to get worse with the economic development, when reached the first turning point at(GDP per capita is 21178.40 yuan), it will get improved. But as the economy continues to develop, the relationship between air quality and economic development will appear in the form of equation (2). That is to say, when the air quality raised to a certain extent, until the GDP per capita reaches 78339.99 yuan (the second turning point), the air quality index will gradually increase, and the air quality will gradually deteriorate.

The traditional EKC test mainly focuses on the relationship between pollutant concentration and GDP, but in the long run, pollutant concentration and GDP are flow indicators, that is, it cannot explain the growth rate effect of these two indicators. In this regard, we also analyzed the relationship between the growth rates of the two indicators, as shown in Figure 1. From the point of view of intuition, it is difficult to judge the rules, so we did an econometric analysis of the two variables based on the equation (3) and equation (4). 


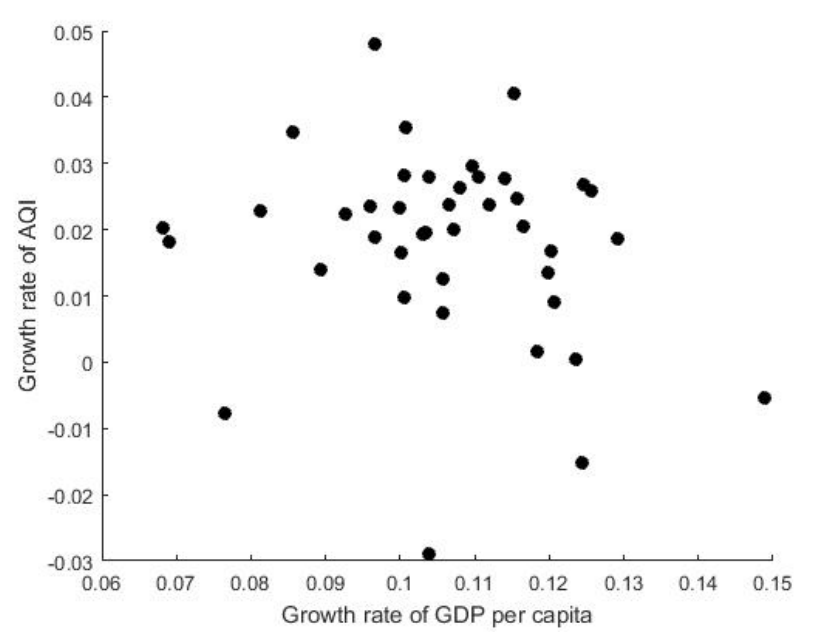

Figure 1. The level of growth rate of AQI and GDP per capita

Different from the traditional EKC test results, though the two variables also meet a U-shaped relationship, there is a huge difference in the turning point. From table 5, we can see that when we consider the initial year variable, the turning point of the U-shaped curve is the point that GDP per 9894.62 yuan. In other words, the growth rate of the air quality index will be reduced first with the growth rate of GDP per capita increased, and the air quality is improved. And when the GDP per capita reaches 9894.62 yuan, the growth rate of AQI will increase with the increase of economic growth rate. When only two variables are considered, the results are similar, and we can get higher level of significance.

Table 5. Results of regression of growth rate model

\begin{tabular}{ccc}
\hline & Equation(3) & Equation(4) \\
\hline $\mathrm{c}$ & 0.3007 & 0.0109 \\
& $(1.4751)$ & $(0.6867)$ \\
$\hat{G}_{i}$ & -2.1086 & $-1.2264^{* * *}$ \\
& $(-1.0897)$ & $(-3.2512)$ \\
$\hat{G}_{i} G_{i, 0}$ & 0.2292 & $0.1364^{* * *}$ \\
& $(1.1309)$ & $(3.0114)$ \\
$G_{i, 0}$ & -0.0167 & \\
& $(-0.7822)$ & \\
$A_{i, 0}$ & $-0.0303 * * *$ & \\
The shape of EKC & $(-5.5393)$ & U-shaped \\
T.P (RMB) & U-shaped & 8032.11
\end{tabular}

Note. The data in the parentheses behind the estimated values are $\mathrm{t}$ statistics, significance levels of regression coefficients: $* 10 \%, * * 5 \%, * * * 1 \%$. The final estimated value data retained four bits after the decimal point, and the $\mathrm{T}$ value retained the bits after the decimal point.

\section{Conclusion}

In this paper, we analyzed the relationship between the air quality index and GDP per capita with the data of 41 main cities in China. By different forms of EKC test we concluded that:

(1) There is a two-way effect mechanism between the air quality index and the level of economic development. Through the two square of the traditional EKC test we found that they satisfy the relationship of U-shaped type curve between AQI and GDP per capita, that is to say, at first AQI will decrease with the increase of GDP per 
capita, after reaching the inflection point (RMB 57593.57), AQI increased with the increase of the per capita GDP. This means that in the early stage of economic development, the air quality will be continued improved, but when the economic development comes to a certain extent, the negative externality gradually emerged, the air quality will gradually become worse with the development of economy.

(2) The results of the three-square EKC test show that it satisfy the relationship of N-shaped type between AQI and GDP per capita, that is to say, the air quality will continue to deteriorate along with the economic development, when GDP per capita reaches the first turning point (21178.40 yuan), the air quality will be gradually improved with the development of economy, with the continuous development of the economy, the relationship will reach another turning point (78339.99 yuan), which means the relationship in the first stage appears again. From this point of view, it is in agreement with the results of the two-square EKC model test.

(3) Unlike traditional EKC test results, though there is a U-shaped relationship between the growth rate of air quality index and the growth rate of GDP per capita, but the turning point is quite different. It means that in the early stage of economic development, the growth rate of AQI will decrease with the increase of the growth rate of GDP per capita. After reaching a turning point, the two variables will reach a trend of the same direction. When the variable of initial year is considered, the turning point is 9894.62 yuan, and if the variable of initial year is not considered, the turning point is 8032.11 yuan.

\section{References}

Andreoni, J., \& Levinson, A. (2001). The simple analytics of the environmental Kuznets curve. Journal of Public Economics, 80(2), 269-286. https://doi.org/10.1016/S0047-2727(00)00110-9

Anjum, Z., Burke, P. J., Gerlagh, R., \& Stern, D. I. (2014, January 1). Modeling the emissions-income relationship using long-run growth rates. CCEP working papers, 1403. https://doi.org/10.1017/S1355770X17000109

Danish, Zhang, B., Wang, B., \& Wang, Z. (2017). Role of renewable energy and non-renewable energy consumption on EKC: Evidence from Pakistan. Journal of Cleaner Production, 156(10), 855-864. https://doi.org/10.1016/j.jclepro.2017.03.203

Egli, H. (2001, December 19). Are cross-country studies of the Environmental Kuznets Curve misleading? New evidence from time series data for Germany. FEEM Working Paper. https://doi.org/10.2139/ssrn.294359

Grossman, G. M., \& Krueger, A. B. (1991). Environmental impacts of the North American Free Trade Agreement. NBER Working Paper, p. 3914.

Lopez, R. (1994). The environment as a factor of production: the effects of economic growth and trade liberalization. Journal of Environmental Economics and Management, 27(2), 163-184. https://dx.doi.org/10.1006/jeem.1994.1032

Magnani, E. (2001). The Environmental Kuznets Curve: development path or policy result? Environmental Modelling \& Software, 16(2), 157-165. https://doi.org/10.1016/S1364-8152(00)00079-7

McConnell, K. E. (1997). Income and the demand for environmental quality. Environment and Development Economics, 2(04), 383-399. https://doi.org/10.1017/S1355770X9700020X

Zhao, J. M., \& Chen, L. Z. (2015). The Research on EKC Inspection of Industrial Pollution Emissions from the Perspective of Nonlinear. Industrial Technology \& Economy, (08), 12-17. https://doi.org/10.3969/j.issn.1004-910X

Zhao, X. K., Li, J. M., \& Wang, J. Y. (2005). Environmental Kuznets curve and its test in China. Nankai Economic Studies, 3(3), 48-54. https://doi.org/ 10.3969/j.issn.1001-4691

Zhong, M. C., \& Zhang, X. G. (2010). Summary about the critique of Environmental Kuznets Curve. China Population Resources and Environment, 20(2), 62-67. https://doi.org/ 10.3969/j.issn.1002-2104

\section{Copyrights}

Copyright for this article is retained by the author(s), with first publication rights granted to the journal.

This is an open-access article distributed under the terms and conditions of the Creative Commons Attribution license (http://creativecommons.org/licenses/by/4.0/). 